\title{
UJI COBA MODEL LOYALITAS PELANGGAN DAN KELANGSUNGAN BISNIS MELALUI HUBUNGAN PELANGGAN PRODUKTIF, AKUNTABILITAS PRODUK DAN LAYANAN SIX SIGMA
}

\author{
Kurnia Isnuwardiati ${ }^{1 *}$, Pudjo Sugito ${ }^{1}$ \\ ${ }^{1}$ Fakultas Ekonomi dan Bisnis, Universitas Merdeka Malang \\ *kurnia.isnuwardiati@unmer.ac.id
}

\begin{abstract}
This study intend to create adaptive solutions to the SME (Small and Medium Enterprises) in the outer circumference culinary Malang order to be sustainable. The reason is because so many problems faced by this business. Therefore, require a fast solution especially by maintaining customer loyalty. For that surely, need to look for a solution through empirical research. Further, the specific objectives of this study wanted to develop a new model to build customer loyalty and business sustainability through productive approach of customer relations, product accountability and governance-based Six Sigma (study of the development of SMEs in the area of culinary outer circumference of Malang). In this study, productive customer relationships, product accountability and governance-based Six Sigma as an exogenous variable, variable customer loyalty and business sustainability as an endogenous variable. First step, structural equation modeling analysis techniques used in the development and simultaneously test theoretical models. Second step, model tries out for selected small and medium industries. Based on the results of research conducted revealed that the productive customer relationships, product accountability and governance-based six sigma significant effect on customer loyalty and business sustainability. So that this result will be a new model in the culinary development of SMEs, particularly in the city of Malang and based on the trial results also reinforce these findings. It means the finding model of customer loyalty and competitiveness is really an adaptive model.
\end{abstract}

Keywords: Customer Loyalty, Product Accountability, Six Sigma

\section{PENDAHULUAN}

Menghadapi gejala perekonomian yang penuh ketidakpastian akhir-akhir ini, industri kuliner bisa jadi menemukan momentum perkembangannya. Hal itu karena kuliner, bagian dari komponen wisata yang dapat menekan kondisi depresi. Namun, tentunya harus melalui berbagai inovasi guna menarik pelanggan, bahkan harus menjadikannya sebagai pelanggan loyal. Sebuah hasil riset menyatakan bahwa industri kiliner merupakan sektor riil yang mempunyai prospek cukup menarik. Tentu saja, perkembangannya ditentukan oleh pengelolanya, utamanya dalam melakukan inovasi. Apalagi sektor kuliner merupakan kelompok industri kreatif yang tentu pula membutuhkan tangan-tangan terampil dalam mengelolanya. Oleh karena itu, pengembangan kemampuan kewirausahaan mutlak diperlukan untuk menyikapi dan mewujudkan industri kuliner yang berkembang.

Dari hasil survey terungkap, UKM kuliner yang terdapat di wilayah lingkar luar Kota Malang ternyata relatif banyak jumlahnya. Berdasarkan informasi yang didapat dari 5 (lima) ketua paguyuban pelaku industri kuliner tersebut, di masing-masing paguyupan memiliki anggota antara 30-45 UKM. Yang menarik, rata-rata jumlah pekerja pada setiap UKM tersebut berjumlah 4-5 orang, diantaranya termasuk pemilik usaha. Tentu dari aspek penyerapan tenaga kerja bisa dianggap cukup baik, ditengah sulitnya mendapatkan kesempatan kerja. 
Namun demikian, UKM kuliner dihadapkan pada banyak persoalan. Pertumbuhannya kurang akseleratif sejalan dengan makin maraknya bisnis kuliner yang berskala besar dengan fasilitas yang juga cukup menarik. Bahkan lokasinyapun kerap berdekatan dengan usaha kuliner beskala kecil. Tentu realitas ini menjadi ancaman serius yang dapat mengganggu kelangsungannya termasuk pula kontribusinya pada perekonomian daerah, baik pada aspek ketenagakerjaan sampai pada kemungkinan meningkatnya angka kemiskinan sebagai akibat dari kebaradaan usaha tersebut yang berpotensi bangkrut.

Untuk itu, pengembangan sektor UKM kuliner menjadi sebuah tumpuan baru. Lebih-lebih Kota Malang sebagai tujuan wisata akhir pekan, sehingga tentunya merupakan pasar potensial bagi industri kuliner. Maka, upaya yang harus dilakukan adalah mengembangkan model bagaimana membangun loyalitas pelanggan yang kemudian dapat mendorong tumbuh dan berkembangnya industri kecil tersebut menjadi lebih prospektif.

Tujuan dilaksanakannya kegiatan penelitian ini adalah untuk melakukan uji coba model membangun loyalitas pelanggan dan business sustainability melalui pendekatan hubungan pelanggan produktif, akuntabilitas produk dan tata layanan berbasis six sigma (studi pengembangan UKM kuliner di wilayah lingkar luar Kota Malang), yang dihasilkan pada tahun pertama. Diharapkan dengan uji coba model baru tersebut, maka akan menjadi model standar dan diharapkan menjadi alat intervensi bagi pemerintah daerah melalui Dinas Perindustrian untuk melakukan pembinaan wirausahawan kuliner tangguh di lingkar luar luar Kota Malang. Singkat kata, intervensi model bagaimana membangun loyalitas pelanggan dan business sustainability tersebut nantinya dapat memicu perkembangan usaha kecil yang bergerak pada sektor kuliner yang kemudian dapat berkontribusi positip pada berputarnya perekonomian wilayah sekitarnya. Bahkan bisa berkontribusi pada pendapatan asli daerah Kota Malang. Tentunya, target khusus lainnya adalah untuk memperbesar kontribusi sektor UKM kuliner ini pada perkembangan perekonomian masyarakat, yang formatnya berwujud meningkatnya kesempatan kerja, makin besar kontribusinya pada PDRB dan sekaligus dapat meningkatkan Pendapatan Asli Daerah (PAD) di wilayah Malang Raya.

Beberapa riset seperti dilakukan Kocuglu \& Kirmaci (2012) pada sebuah hasil penelitiannya yang berjudul Customer Relationship Management and Customer Loyalty: Survey in The Sector of Banking mengungkapkan bahwa terdapat pengaruh yang signifikan diantara kedua variable penelitian tersebut. Hal itu terbukti dari koefisien signifikansi sebesar 0.002 . Selanjutnya, Coltmana, Devinney \&. Midgley (2012) dalam hasil risetnya tentang Customer Relationship Management and Firm Sustainability menemukan bahwa terdapat hubungan positip dan kuat pada kedua variable penelitian tersebut, Ini memberikan indikasi bahwa jika hubungan dengan pelanggan berjalan baik maka akan berdampak tehadap pada kelangsungan bisnis.

Gresham A. \& Stephen F. (2007) pada hasil penelitiannya yang berjudul Using Six Sigma to Measure and to Improve Customer Loyalty mendapatkan bahwa six sigma memiliki dampak positip pada loyalitas pelanggan. Maknanya bahwa implementasi sigma dapat meningkatkan loyalitas pelanggan. Peneliti lain, Goriwondo and Maunga (2012) dalam artikel hasil penelitiannya dengan judul Lean Six Sigma Application for Sustainable Production: A Case Study for Margarine Production in Zimbabwe juga mengungkapkan dalam hasil analisisnya bahwa six sigma berpengaruh nyata terhadap kelangsungan produksi pada industry margarine di Zimbabwe. Dengan demikian, sigma tidak hanya berpengaruh tehadap kualitas tata layanan, melainkan juga berpengaruh terhadap kelangsungan sebuah bisnis.

Keterkaitan akuntabilitas produk dengan loyalitas pelanggan pernah diteliti 
oleh Chin dan Gainer (2012) bahwa akuntabilitas produk memiliki keterkaitan dengan loyalitas pelanggan. Penelitian yang dilakukan pada industri makanan dan minuman ini menggunakan 133 sampel dan besar koefisien korelasi kedua variable tersebut sebasar 0.57. Hasil riset ini juga tebukti pada penelitian Kajanova (2013) bahwa akuntabilitas produk berpengaruh signifikan terhadap loyalitas pelanggan pada industri rumah makan waralaba asing di New Delhi.

Riset-riset tentang hubungan antara loyalitas pelanggan dengan kelangsungan bisnis juga telah banyak dilakukan dan hampir semuanya mempunyai hubungan kuat dan searah. Maknanya, loyalitas pelanggan sangat penting untuk sustainability sebuah entitas bisnis. Penelitian tersebut dilakukan oleh East \& Gendal (2012), juga Hammond \& Lommax (2012) dengan obyek riset masing-masing bisnis kuliner di Brisbane dan industri asuransi di Miami, Amerika Serikat. Hasil penelitian terkini dilakukan Gavami dan Oliyae (2013) dengan judul The Impact of Loyalty Customer on Profitability and Sustainability terungkap bahwa loyalitas pelanggan bukan hanya berdampak positip terhadap kemampulabaan, tetapi sekaligus juga pada kelangsungan bisnis.

\section{METODE}

Penelitian dengan obyek UKM kuliner di wilayah lingkar luar Kota Malang ini menggunakan pendekatan Research and Development $(R \& D)$. Metode ini dipilih karena pada penelitian ini dilakukan pengembangan dan uji coba model. Tahapantahapan pelaksanaannya, mulai dari dari tahapan pengembangan, penerapan dan tahapan evaluasi. Setelah tahapan kegiatan uji coba model dilaksanakan, maka akan dilakukan pengumpulan data/pendapat baik melalui kuesioner, pengamatan langsung tentang hambatan, tantangan sekaligus manfaat yang dirasakan dari hasil uji coba model pengembangan UKM kuliner tersebut.

Berdasarkan evaluasi model yang telah dilakukan, peneliti akan akan melakukan standardisasi model. Tahap berikutnya, uji coba model lanjutan dengan pendekatan hubungan pelanggan produktif, akuntabilitas produk dan tata layanan berbasis six sigma yang telah dihasilkan dari kegiatan sebelumnya. Secara ringkas, kegiatan penelitian ini akan dilaksanakan dalam enam (6) langkah yang secara bertahap meliputi (a) Penyusunan modul model pengembangan UKM Kuliner dengan pendekatan hubungan pelanggan produktif, akuntabilitas produk dan tata layanan berbasis six sigma, (b) Pemilihan UKM Kuliner sebagai tempat uji coba (10 UKM). Kegiatan ini akan menggunakan pertimbangan kesediaan UKM dan masukan dari Dinas Perindustrian Wilayah Malang Raya, (c) Kegiatan uji coba (5 bulan) dengan pendampingan berkala. Pada saat dilakukan uji coba model, peneliti akan melakukan pendampingan dan monitoring secara berkala. Tujuannya, agar pelaksanaan uji coba sesuai dengan modul dan harapan peneliti, (d) Evaluasi dan analisis pelaksanaan uji coba. Setelah uji coba selesai dilaksanakan, peneliti akan melakukan analisis dan evaluasi hasil uji coba, untuk mendapatkan informasiinformasi relevan terkait perkembangan hasil uji coba, (e) Penyempurnaan model dengan metode diskusi terarah (FGD), yang melibatkan pakar yang concern dengan pengembangan UKM dan (f) Pemantapan dan standardisasi model. Kegiatan ini bertujuan dalam rangka untuk mendapatkan model adaptif.

\section{HASIL DAN PEMBAHASAN}

Berdasarkan hasil analisis structural equation model (SEM) yang telah dilakukan, secara empiris model yang telah didisain dinyatakan sesuai untuk kegiatan penelitian ini. Hal itu karena semua hasil evaluasi uji goodness of fit index ternyata baik dan hanya 1 (satu) yang dalam kategori marginal yaitu CFI (Comparative Fit Index), yang mensyaratkan cut-off value nilainya $\geq 0.95$. Sementara hasil analisis CFI hanya sebesar 0.876 yang lebih kecil dari 0.95. Dengan demikian, untuk besaran nilai CFI hanya berada pada kategori marginal, sebagaimana 
tertera pada tabel 1 tentang hasil uji kesesuaian model penelitian, sebagai berikut.

Tabel 1. Hasil Uji kesesuaian Model Penelitian

\begin{tabular}{lccc}
\hline $\begin{array}{l}\text { Goodness of } \\
\text { Fit Index }\end{array}$ & $\begin{array}{c}\text { Cut- } \\
\text { off } \\
\text { Value }\end{array}$ & $\begin{array}{c}\text { Hasil } \\
\text { Anali } \\
\text { sis }\end{array}$ & $\begin{array}{c}\text { Evaluasi } \\
\text { Model }\end{array}$ \\
\hline $\begin{array}{l}\mathrm{X}^{2}-\text { Chi- } \\
\text { square }\end{array}$ & $\begin{array}{c}\mathrm{P}=5 \%, \\
\text { Chi- } \\
\text { Square }\end{array}$ & $\begin{array}{c}22.34 \\
\text { Baik }\end{array}$ & Baik \\
$\begin{array}{l}68.673 \\
\text { Signifinacance } \\
\text { Probability }\end{array}$ & $\geq 0.05$ & 0.124 & Baik \\
\hline RMSEA & $\leq 0.08$ & 0.021 & Baik \\
\hline GFI & $\geq 0.90$ & 0.985 & Baik \\
\hline AGFI & $\geq 0.90$ & 0.990 & Baik \\
\hline CMIN/DF & $\leq 2.00$ & 1.049 & Baik \\
\hline TLI & $\geq 0.95$ & 0.996 & Baik \\
\hline CFI & $\geq 0.95$ & 0.876 & Marginal \\
\hline SFI:
\end{tabular}

Sumber: data pimer diolah, 2015

Dengan demikian, model pengembangan UKM Kuliner di Wilayah Lingkar Luar Kota Malang dapat disusun sebagaimana yang didisain dalam kerangka model, yang telah disusun peneliti sebagai berikut.

Gambar 1. Model Pengembangan UKM Kuliner

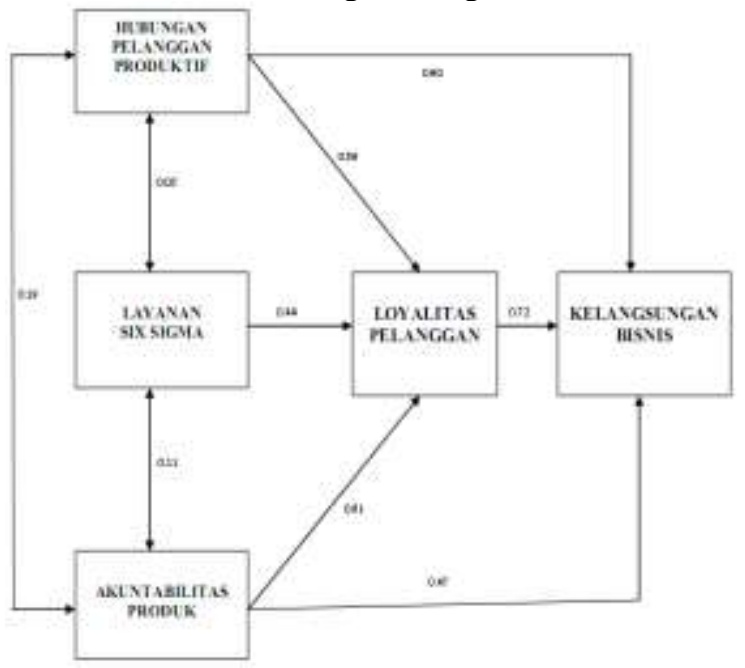

Sumber: Hasil Olah Data Primer, 2016.

Berdasarkan gambar 1, terungkap bahwa hubungan pelanggan produktif, akuntabilitas dan layanan six sigma berpengaruh terhadap kelangsungan bisnis dengan koefisien masing-masing $0.59,0.44$ dan 0.61. Ketiga variabel tersebut juga mempunyai pengaruh langsung terhadap kelangsungan bisnis dengan koefisien masing-masing 0.50 dan 0.47. Sedangkan koefisien pengaruh layanan six sigma terhadap loyalitas pelanggan sebesar 0.44 dan pengaruh loyalitas pelanggan terhadap kelangsungan bisnis mempunyai koefisien 0.72 .

Selanjutnya, model teoritik tersebut di ujicobakan pada 10 (sepuluh) UKM terpilih. Kemudian, setelah model tersebut dilakukan uji coba pada 10 (sepuluh) sampel UKM Kuliner di wilayah lingkar luar Kota Malang, yang pelaksanannya disertai dengan pendampingan secara berkala maka dalam kurun waktu selama 5 (lima) bulan. Terungkap bahwa omset penjualannya mengalami peningkatan yang relatif signifikan dibandingkan sebelum dilaksanakan uji coba. Hal tersebut terungkap secara jelas pada gambar perbandingan omset penjualan sebelum dan sesudah uji coba model berikut ini.

Gambar 2. Perbandingan omset sebelum dan sesudah uji coba model (Rp Juta)

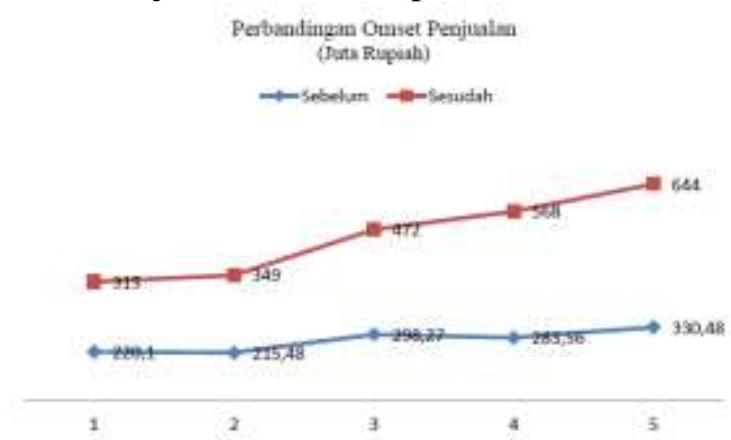

Sumber: Hasil Olah Data Primer, 2016.

Berdasarkan gambar 2, terungkap bahwa implementasi uji coba model mempunyai dampak nyata pada peningkatan omset penjualan. Hal tersebut terlihat jelas pada perbandingan omset antara sebelum dan sesudah uji coba model. Maknanya, model tersebut dapat dinyatakan cukup adaptif dalam rangka pengembangan UKM Kuliner di Wilayah Lingkar Luar Kota Malang.

Selanjutnya, berdasarkan data hasil uji coba model tersebut, hasilnya dianalisis dengan menggunakan teknik analisis uji beda sebagaimana telah dilakukan dengan 
menggunakan program olah data SPSS 22.0. Tujuannya untuk mengetahui tingkat signifikansi perbedaan sebelum dan sesudah dilakukan uji coba implementasi model pada usaha kecil menengah kuliner terpilih. Dengan teknik analisis uji beda, diperoleh hasil yang dapat digunakan untuk menentukan signifikansi perbedaan antara sebelum dan sesudah uji model. Untuk itu, keputusannya bisa dilihat dari tabel paired samples test, sebagai berikut:

Tabel 2. Paired Sample Test

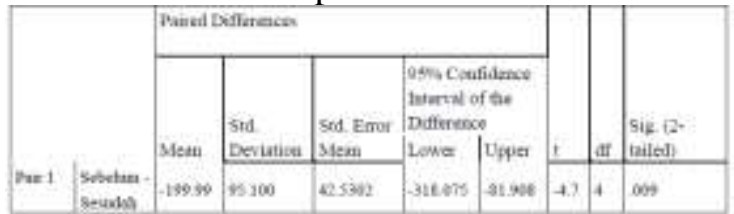

Sumber: Hasil Olah Data Primer, 2016

Berdasarkan tabel 2, tentang paired samples test terungkap bahwa dengan tingkat sigifikansi sebesar 0.009 , berarti terdapat perbedaan signifikan antara sebelum dan sesudah uji coba model. Dengan kata lain, implementasi model memberikan manfaat nyata pada peningkatan penjualan sebagai indikator kelangsungan bisnis pada UKM Kuliner di Wilayah Lingkar Luar Kota Malang.

Temuan hasil uji coba dan analisis uji beda tersebut sejalan dengan pendapat Coltmana, Devinney \&. Midgley (2012) dalam hasil risetnya tentang Customer Relationship Management and Firm Sustainability menemukan bahwa terdapat hubungan positip dan kuat pada kedua variable penelitian tersebut, Ini memberikan indikasi bahwa jika hubungan dengan pelanggan berjalan baik maka akan berdampak tehadap pada kelangsungan bisnis. Kemudian, Gresham A. \& Stephen F. (2007) pada hasil penelitiannya yang berjudul Using Six Sigma to Measure and to Improve Customer Loyalty mendapatkan bahwa six sigma memiliki dampak positip pada loyalitas pelanggan. Maknanya bahwa implementasi sigma dapat meningkatkan loyalitas pelanggan. Juga, sesuai dengan temuan Goriwondo and Maunga (2012) dalam artikel hasil penelitiannya dengan judul Lean Six Sigma Application for Sustainable Production: A Case Study for Margarine Production in Zimbabwe yang mengungkapkan bahwa six sigma berpengaruh nyata terhadap kelangsungan produksi pada industry margarine di Zimbabwe. Kemudian, memperkuat pendapat Chin dan Gainer (2012) bahwa akuntabilitas produk memiliki keterkaitan dengan loyalitas pelanggan. Penelitian yang dilakukan pada industri makanan dan minuman ini menggunakan 133 sampel dan besar koefisien korelasi kedua variable tersebut sebasar 0.57. Hasil riset ini juga sejalan dengan penelitian Kajanova (2013) bahwa akuntabilitas produk berpengaruh signifikan terhadap loyalitas pelanggan pada industri rumah makan waralaba asing di New Delhi. Hasil penelitian ini juga linear dengan yang dilakukan East \& Gendal (2012), juga Hammond \& Lommax (2012) dengan obyek riset masing-masing bisnis kuliner di Brisbane dan industri asuransi di Miami, Amerika Serikat. Bahkan sejalan dengan hasil penelitian yang dilakukan Gavami dan Oliyae (2013) dengan judul The Impact of Loyalty Customer on Profitability and Sustainability bahwa loyalitas pelanggan bukan hanya berdampak positip terhadap kemampulabaan, tetapi sekaligus pada kelangsungan bisnis. Dengan demikian, temuan model pada gambar 1 merupakan model final pada penelitian pengembangan loyalitas pelanggan dan kelangsungan UKM kuliner di lingkar luar Kota Malang. Sehingga, untuk kepentingan standardisasi model pengembangan UKM Kuliner di lingkar luar Kota Malang diperlukan analisis lanjutan dengan menggunakan teknik analisis diskriminan.

Selain itu, sejalan dengan pendapat Coltmana, Devinney \&. Midgley (2012) dalam hasil risetnya tentang Customer Relationship Management and Firm Sustainability menemukan bahwa terdapat hubungan positip dan kuat pada kedua variable penelitian tersebut, Ini memberikan indikasi bahwa jika hubungan dengan pelanggan berjalan baik maka akan berdampak tehadap pada kelangsungan 
bisnis. Kemudian, Gresham A. \& Stephen F. (2007) pada hasil penelitiannya yang berjudul Using Six Sigma to Measure and to Improve Customer Loyalty mendapatkan bahwa six sigma memiliki dampak positip pada loyalitas pelanggan. Maknanya bahwa implementasi sigma dapat meningkatkan loyalitas pelanggan.

Disamping itu, sesuai dengan temuan Goriwondo and Maunga (2012) dalam artikel hasil penelitiannya dengan judul Lean Six Sigma Application for Sustainable Production: A Case Study for Margarine Production in Zimbabwe yang mengungkapkan bahwa six sigma berpengaruh nyata terhadap kelangsungan produksi pada industry margarine di Zimbabwe. Kemudian, memperkuat pendapat Chin dan Gainer (2012) bahwa akuntabilitas produk memiliki keterkaitan dengan loyalitas pelanggan. Penelitian yang dilakukan pada industri makanan dan minuman ini menggunakan 133 sampel dan besar koefisien korelasi kedua variable tersebut sebasar 0.57. Hasil riset ini juga sejalan dengan penelitian Kajanova (2013) bahwa akuntabilitas produk berpengaruh signifikan terhadap loyalitas pelanggan pada industri rumah makan waralaba asing di New Delhi. Hasil penelitian ini juga linear dengan yang dilakukan East \& Gendal (2012), juga Hammond \& Lommax (2012) dengan obyek riset masing-masing bisnis kuliner di Brisbane dan industri asuransi di Miami, Amerika Serikat. Bahkan sejalan dengan hasil penelitian yang dilakukan Gavami dan Oliyae (2013) dengan judul The Impact of Loyalty Customer on Profitability and Sustainability bahwa loyalitas pelanggan bukan hanya berdampak positip terhadap kemampulabaan, tetapi sekaligus pada kelangsungan bisnis. Dengan demikian, temuan model pada gambar 1 merupakan model final dan bersifat standar pada penelitian pengembangan loyalitas pelanggan dan kelangsungan UKM kuliner di lingkar luar Kota Malang.

\section{KESIMPULAN}

Berdasarkan hasil uji coba model pada sepuluh UKM Kuliner di wilayah lingkar Kota Malang terungkap jelas berdampak positip pada peningkatan penjualan, yang tentu sebagai salah satu indikator dari kelangsungan bisnis. Dengan demikian, model membangun loyalitas pelanggan \& business sustainability: sebuah pendekatan baru melalui hubungan pelanggan produktif, akuntabilitas produk dan tata layanan berbasis six sigma yang telah didesain dapat diterapkan pada semua usaha kecil kuliner di wilayah obyek yang diteliti. Tentu, dinamika kompetisi yang terjadi menuntut dilakukannya modifikasi model secara berkala dan disesuaikan dengan kelompok dan jenis usahanya. Sehingga, implementasi model tersebut akan berkontribusi lebih nyata pada kelangsungan bisnis, utamanya pada kelangsungan UKM Kuliner di Wilayah Lingkar Luar Kota Malang. Maknanya, loyalitas pelanggan hendaknya dibangun melalui hubungan pelanggan yang bersifat produktif, tata layanan berbasis six sigma dan akuntabilitas produk. Karena itu, dalam jangka pendek, hanya dengan model solusi itulah, loyalitas pelanggan akan meningkat dan secara langsung akan menjamin kelangsungan bisnisnya.

\section{DAFTAR PUSTAKA}

Boone LE. 2007. Business Management in the Changing Era. The Fourth Edition. Philadelpia: Mc.Millan Publishing.

Chin CO, Gainer LP. 2012. Product Accountability, Customer Loyalty and Firm Performance. Journal of Marketing Research. (53:4) 35-42.

Devinney W, Midgley F. 2012. Customer Relationship Management and Firm Sustainability.Jurnal of Customer Relationship Management. 12(24): 197-208.

East R, Gendal P. 2012. Consumer Loyalty:Singular,Additive or Interactive. Jurnal of Business. 4(25): 293-313 
George ML, Rowlands, David, Price, Mark and John M. 2005.The Lean Six Sigma Pocket Tool Book. Washington: McGraw-Hill

Ghavany A, Olyae A. 2013. The Impact of Loyalty Customer on Profitability and Sustainability. Jurnal of Economics and Social Research. 1(34): 20-30.

Gitlow J, Howard S, David ML. 2005. Six Sigma for Green Belts and Champions.

The second Edition. New York: Prentice Hall.

Goriwondo WM, Maunga N. 2012. Lean Six Sigma Application for Sustainable Production: A Case Study for Margarine Production in Zimbabwe. International Journal of Innovative Technology and Exploring Engineering. 1(5): 160-170.

Goriwondo G, Maunga R. 2012. Lean Six Sigma Application for Sustainable Production. Jurnal of African Business. 10(22): 77-90.

Gresham A, Stephen F. 200. Using Six Sigma to Measure and to Improve Customer Loyalty. Jurnal of Customer Relationship Management. 7(15): 112123.

Hammond K, Lomax W. 2012. The Antecedents of Customer Loyalty: An Empirical Investigation in Life Insurance Context. Jurnal of International Business Studies. 13(5): 177-190.

Kajanova J. 2013. Study on Product Accontability in the Franchice Reastaurant. Business Management and Education Jurnal. 9(2): 157-17.

Kottler P, Keller MT. 2005. Building Customer Loyalty. The Student Edition. Washington: Longman Inc.

Kocuglu H, Kirmaci OD. 2012. Customer Relationship Management and Customer Loyalty: Survey in The Sector of Banking. Jurnal of Customer Relationship Management. 12(24): 222-235.

Pande PS, Neuman RP, Roland RC. 2013. The Six Sigma Way: Team Fieldbook, An Implementation Guide for Process
Improvement Teams. San Fransisco: McGraw- Hill. .

Stone J, Dwivedi JH, Jabbra JJ. 2010. Good Corporate Governance in Business, The Fifth Edition, New Delhi: Richard Irwin Publication.

Shapiro C. 2011. Theory of Business Strategy. RAND Jurnal of Economics, 20(5): 125-137.

Tim RC, Timothy MD, Midgley DF. 2012. Customer Relationship Management and Firm Performance. Journal of Marketing Research. (41:3): 293-313.

Yamin S, Kurniawan H. 2009. Structural Equation Modeling: Belajar Lebih Mudah Teknik Analisis Data Kuesioner dengan LISREL-PLS. Buku Seri Kedua. Jakarta: Salemba Infotek. 